\title{
MEMÓRIAS DE PROFESSORAS: A ESCOLHA DA PROFISSÃO DOCENTE
}

\author{
Layza Karla Miliorini ${ }^{(*)}$ \\ Alboni Marisa Dudeque Pianovski Vieira ${ }^{(* *)}$
}

\section{INTRODUÇÃO}

Esta pesquisa foi desenvolvida a partir do resultado de investigações realizadas por um grupo de pesquisadores, o qual percebeu a necessidade de promover espaços de intervenção na formação continuada de professores em diferentes níveis de ensino, para a ressignificação de suas aprendizagens. A formação continuada é uma das ferramentas para a conscientização e a sensibilização dos professores em relação as suas práticas, bem como à tomada de decisão para potencializar as aprendizagens dos discentes nessa realidade complexa em que está situada a escola.

A trabalho da ressignificação de aprendizagens justifica-se, uma vez que, como salienta Candau, '[...] a formação continuada não pode ser concebida como um processo de acumulação (de cursos, palestras, seminários, etc., de conhecimentos ou de técnicas), mas, sim, como trabalho de reflexividade crítica sobre as práticas" (1997, p. 64).

Assim, o trabalho aqui apresentado aconteceu por meio das observações de um grupo de professoras do ensino fundamental, durante um curso de formação continuada oferecido pelo grupo de pesquisa de uma instituição privada de educação superior, em aprendizagem e conhecimento na formação continuada, durante o ano de 2017, na cidade de Curitiba, Paraná.

O programa de Formação Continuada teve duração de dois meses, com encontros semanais de duas horas, os quais ocorreram na própria instituição em que as professoras trabalhavam, em um horário extracurricular.

Esses encontros foram estruturados de forma a privilegiar momentos de tomada de consciência e regulação das atividades que envolvem a prática docente. Todos eles iniciavam com a chamada "revisão da tarefa", cujo objetivo era retomar o tema abordado no encontro anterior, que,

\footnotetext{
${ }^{(*)}$ Licenciada em Pedagogia. Mestranda no Programa stricto sensu em Educação da Pontifícia Universidade Católica do Paraná (PUC-PR). Plataforma lattes: <http://lattes.cnpq.br/2259384769405213>. Orcid: <https://orcid.org/0000-00017499-0746>. E-mail: layza.miliorini @gmail.com.

${ }^{(* *)}$ Licenciada em Pedagogia, bacharel em Direito, mestre em Gestão de Instituições de Educação Superior, mestre em Educação, doutora em Educação. Professora do Programa de Pós-graduação em Educação (Mestrado e Doutorado) da PUC-PR. Editora da Revista Diálogo Educacional da PUC-PR. Plataforma lattes: <http://lattes.cnpq.br/ 0198429449537597>. Orcid: http://orcid.org/0000-0003-3759-0377. E-mail: alboni@alboni.com.
} 
por sua vez, deveria ter sido aplicado à realidade por meio de um instrumento de pesquisa. $\mathrm{O}$ segundo momento da formação, denominado "disparador", discorria acerca de uma temática específica relacionada ao tema do encontro, apresentada de forma oral ou dinâmica. $\mathrm{O}$ terceiro momento era o da "roda de conversa", caracterizado como o espaço de reelaboração em grupo do tema do dia, alimentado por uma consigna inicial. No quarto momento, os professores eram convidados e instrumentalizados a pesquisarem, no intervalo entre os encontros, as suas práticas. $\mathrm{O}$ quinto momento era o da "avaliação", sendo, então, apresentadas perguntas a serem respondidas no grupo.

Uma das tarefas sugeridas para esse grupo de professoras foi escrever seu memorial (individualmente), a fim de destacar sua história de vida profissional e momentos que marcaram a escolha da profissão. Em paralelo a essas tarefas e encontros, foram realizadas entrevistas semiestruturadas.

O estudo do memorial proporciona ao professor reflexão sobre a retomada de experiências e atitudes que o levaram a ser o professor que é hoje, uma vez que a prática docente é resultado de experiências e de um processo de formação que ocorreram ao longo de sua carreira.

Nesse sentido, questiona-se: Como o professor se tornou o professor que é hoje? De que maneira a prática pedagógica é influenciada pelo seu percurso de vida profissional e pessoal?

Nóvoa ressalta que “[...] hoje, sabemos que não é possível separar o eu pessoal do eu profissional, sobretudo numa profissão fortemente impregnada de valores e de ideias e muito exigente do ponto de vista do empenhamento e da relação humana” (NÓVOA, 1992, p. 7).

O professor, enquanto profissional da educação, manifesta crenças, cultura, hábitos, inquietações, interesse e/ou desinteresse durante sua carreira. A construção de sua história profissional é marcada por fatos marcantes que contribuem direta ou indiretamente para que ele se desenvolva em seu ofício.

Para entender como um professor desenvolveu sua carreira, é importante estudar e compreender suas experiências ao longo de sua trajetória profissional. Assim,

A carreira docente configura-se como um processo de formação permanente e de desenvolvimento pessoal e profissional do adulto-professor, que compreende não apenas os conhecimentos e competências que o mesmo constrói na formação, mas também a pessoa que ele é, com todas as suas crenças, idiossincrasias e história de vida, e o contexto em que exerce a atividade docente (HARGREAVES; FULLAN, 1992 apud GONÇALVES, 2009, p. 24). 
O estudo da formação ao longo da vida é o caminho fundamental para entender os desafios e o desenvolvimento profissional e pessoal dos professores. A carreira é um dos elementos para compreender esse desenvolvimento, uma vez que a maneira de ser professor varia e depende de um constante processo de formação, desenvolvimento profissional, construção de carreira, articulados ao contexto social e cultural de cada professor.

Complementando essa ideia, Tardif (2012) ressalta que os saberes profissionais das professoras são influenciados e moldam a identidade do professor e isso reflete a relação do professor com o ensino e a aprendizagem dele e de seus alunos. O saber docente é socialmente construído, uma vez que sua atuação pedagógica dispõe de vários conhecimentos construídos ao longo de sua trajetória. Assim, “[...] o saber docente se compõe, na verdade, de vários saberes provenientes de diferentes fontes" (TARDIF, 2012, p. 33).

\section{HISTÓRIA DE VIDA DOS PROFESSORES}

Segundo Goodson (1992), o ouvir a voz do professor, quando este fala de seu trabalho, ensina-nos que o (auto)biográfico, isto é, a vida, é de grande interesse para compreender o seu ensino.

No processo de tomada de consciência sobre seu percurso de vida, o indivíduo demostra sua subjetividade e analisa sua trajetória de vida, a fim de buscar significados para a construção de sua identidade profissional. A escrita do memorial possibilita ao professor revelar seus anseios, expectativas e o caminho que o levou à profissão docente.

Ao manifestar sua história de vida marcada por acontecimentos profissionais e pessoais que o caracterizam no sujeito que é hoje, faz-se necessário reconhecer a imagem que o professor constrói de si mesmo perante a sociedade, o que faz parte de um processo contínuo de formação de identidade profissional.

Ao conhecer a história de vida do professor, é possível compreender e estabelecer relações entre o ensino e a prática docente. Para Moita (1992, p. 116), as histórias de vida dos professores "[...] permitem compreender de um modo global e dinâmico as interações que foram acontecendo nas diversas dimensões de uma vida. Só uma história de vida permite captar o modo como cada pessoa, permanecendo ela própria, se transforma”.

A autora citada ressalta que a formação do sujeito na sua totalidade está diretamente ligada à construção de sua identidade pessoal e profissional. Ao falar de formação, Moita ressalta que: 
Ninguém se forma vazio. Formar-se supõe troca, experiência, interações sociais, aprendizagens, um sem fim de relações. Ter acesso ao modo como cada pessoa se forma é ter em conta a singularidade da sua história e sobretudo o modo singular como age, reage e interage com os seus contextos. Um percurso de vida é assim um percurso de formação, no sentido em que é um processo de formação [...] (MOITA, 1992, p. 115).

A formação, nesse sentido, é um processo dinâmico e contínuo, que considera a trajetória completa do sujeito e o contexto em que está inserido. É nesse processo contínuo de formação que se constrói a identidade pessoal e profissional de uma pessoa. Moita define identidade profissional como:

É uma construção que tem uma dimensão espaciotemporal, atravessa a vida profissional desde a fase da opção pela profissão até à reforma, passando pelo tempo concreto da formação inicial e pelos diferentes espaços institucionais onde a profissão se desenrola. É construída sobre saberes científicos e pedagógicos como experiências feitas, das opções tomadas, das práticas desenvolvidas, das continuidades e descontinuidades, que ao nível das representações quer ao nível do trabalho concreto (MOITA, 1992, p. 116).

O professor, ao compartilhar suas histórias, revive, recorda e recupera experiências profissionais passadas. Assim, “[...] repensar o passado, ressignificá-lo, pensar e ressignificar o futuro são ações que supõem indagar o presente, no presente, superando mitos e ilusões, colocando em questão soluções que se têm apresentado como imediatas e rápidas” (KRAMER, 1998, p. 20).

Ao interpretar as narrativas, percebe-se a presença dos aspectos afetivos e cognitivos, o modo como a pessoa define o mundo, sua maneira de ser, sua memória e contexto sociocultural, como caraterísticas influenciadoras nos discursos dos professores. Essas características fazem parte e contribuem para a construção da identidade docente. Desse modo, "[...] a identidade não é um dado adquirido, não é uma propriedade, não é um produto. A identidade é um lugar de lutas e de conflitos, é um espaço de construção de maneiras de ser e se estar na profissão" (NÓVOA, 1992, p. 16).

No processo de formação, pode considerar-se a dinâmica em que se vai construindo a identidade da pessoa. Processo em que cada pessoa, permanecendo ela própria e reconhecendo-se mesma ao longo de sua história, forma-se, transforma-se, em interação (MOITA, 1992).

Ao se falar em história de vida dos professores, é preciso considerar a importância de recordar fatos e do papel da memória nesse processo. De acordo com Halbwachs,

[...] a história não é todo o passado, mas também não é tudo aquilo que resta do passado. Ou, se o quisermos, ao lado de uma história escrita, há uma história viva que 
se perpetua ou se renova através do tempo e onde é possível encontrar um grande número dessas correntes antigas que haviam desaparecido somente na aparência (HALBWACHS,1990, p. 66).

Nesse sentido, a construção da memória de um indivíduo é uma combinação das memórias dos diversos grupos dos quais ele participa e sofre influência, seja na família, na escola, em um grupo de amigos ou no ambiente de trabalho. O indivíduo interage por meio de dois tipos de memória (individual e coletiva) e isso se dá à medida que “[...] o funcionamento da memória individual não é possível sem esses instrumentos que são as palavras e as ideias, que o indivíduo não inventou, mas que toma emprestado de seu ambiente" (HALBWACHS, 1990, p. 72). Portanto, é a partir das relações individuais e coletivas que construímos o que a memória e as lembranças manifestam.

Nessa perspectiva, o movimento de lembrar constitui-se principalmente na reconstrução de acontecimentos, que se dão a partir de interesses e preocupações de cada indivíduo. As memórias que os professores constroem acerca de sua formação acadêmica ajudam a descortinar aspectos da formação que remetem à subjetividade do professor.

Escrever as trajetórias de vidas profissionais requer uma organização do pensamento, um recordar de memórias passadas. Trata-se, nesse sentido, de um momento no qual se pode criar novos significados as nossas experiências. Nóvoa (1997) chama-nos a atenção à necessidade de trazer à tona os saberes dos docentes, uma vez que:

O saber dos professores - como qualquer outro tipo de saber de intervenção social não existe antes de ser dito. A sua formulação depende de um esforço explicitado e de comunicação, e é por isso que ele se reconhece, sobretudo, através do modo como é contado aos outros. Os professores possuem um conhecimento vivido (prático), mas que é dificilmente transmissível a outrem. Ora, na medida em que, no campo educativo o saber não preexiste à palavra (dita ou escrita), os conhecimentos de que os professores são portadores tendem a ser desvalorizados do ponto de vista social e científico (NÒVOA, 1997, p. 36).

Do ponto de vista da investigação, essas narrativas de formação constituem-se como instrumentos valiosos, porque trazem aos pesquisadores informações sobre o que pensam os professores a respeito de suas histórias de vida, posicionando-os como autores de suas narrativas e não simplesmente como informantes. Do ponto de vista da formação, o registro de memórias permite reflexões e novos olhares para os processos vividos, a realidade, o mundo e a cultura, 
possibilitando que os professores compreendam como se apropriaram das experiências formativas, dando sentido a sua trajetória e projetando suas expectativas.

\section{METODOLOGIA}

Considerando que essa pesquisa analisou as vozes, as falas e os discursos dos professores para conhecer o que estes dizem sobre sua história profissional, a metodologia utilizada foi a fenomenologia hermenêutica, que por sua vez vem sendo usada na pesquisa em educação como recurso interpretativo para produzir conhecimento. É uma atitude interpretativa, em que sujeito e objeto só podem ser compreendidos por meio da linguagem, que é fruto tanto do pensamento, como das experiências práticas.

A fenomenologia representa uma corrente filosófica que eleva a importância do sujeito no processo da construção do conhecimento, em conexão com o contexto em que está inserido, como sua condição econômica, sua cultura, etc., elementos que são considerados como pressupostos naturais no estudo de algum assunto específico.

Ao perceber novas características do fenômeno, ou ao encontrar, no outro, interpretações ou compreensões diferentes, surge uma nova interpretação que levará a outra compreensão (FAZENDA, 2000).

Por sua vez, a hermenêutica é uma técnica de interpretação. O pesquisador é o intérprete da realidade e segundo Trevisan, Tomazetti e Rossatto (2010, p. 372), tem o objetivo de "[...] tornar compreensível o objeto da investigação não como ele se apresenta de imediato, mas por meios interpretativos dentro do seu contexto histórico de acontecimentos".

Costa (2007, p. 92) corrobora essa assertiva ao comentar que "[...] quem pratica/participa da produção de relatos/narrativas/histórias sobre as pessoas, processos e coisas do mundo, participa do processo social de atribuição de sentido".

A hermenêutica permite a interpretação como uma possível metodologia para as pesquisas em ciências humanas, buscando na compreensão o método apropriado para repensar e analisar a complexidade dos discursos expressos pelos sujeitos da pesquisa. A compreensão e a interpretação subjazem a todo trabalho realizado, isto é, a realização ou resultado de um trabalho de pesquisa é o resultado de um processo de explicação, compreensão e interpretação da realidade.

A proposta fenomenológica hermenêutica não apenas descreve e analisa as vozes, as falas e a linguagem do sujeito, mas interpreta o que este meio comunica rumo à transformação dessa 
prática. Permitir ao professor um momento de pesquisa, reflexão e interpretação de sua própria prática é um caminho à construção de conhecimentos e de transformação do contexto em que está inserido.

Desse modo, foi realizada uma análise das histórias de vidas profissionais dos professores que participaram de um programa de formação continuada. Foi solicitado como tarefa de um dos encontros que elaborassem um memorial, com a seguinte proposta: você fará uma narrativa escrita, contando sua história profissional, de tal forma que destaque os momentos mais importantes de aprendizagem que viveu (em família, com amigos, na escola - desde a educação infantil até sua formatura e primeiras ações profissionais) e que tenham contribuído para a formação do profissional que você é hoje.

A construção do memorial possibilita aos docentes construir, redescobrir e ressignificar suas práticas. Além disso, é um rico instrumento para descobrir e repensar a identidade profissional. Romanowski (2010, p. 18) ressalta que esse processo de formação identitária acontece no “[...] desenvolvimento permanente, coletivo e individual, no confronto do velho com o novo, frente aos desafios de cada momento sócio-histórico". Essa perspectiva parte do pressuposto de que a formação é contínua, que o conhecimento não é construído de maneira individual, mas das relações que cada sujeito tem com o meio no qual está inserido.

Para complementar as informações, foram realizadas entrevistas semiestruturadas, em outro período que não coincidisse com o horário da formação continuada, previamente agendado e no local de trabalho dos professores. Estavam presentes apenas o entrevistador e o entrevistado. O entrevistado recebia um protocolo de orientações e um gravador. Após a realização das entrevistas, as entrevistas eram desgravadas e transcritas pela equipe de apoio até chegar na sua versão final.

\section{ANALISE E DISCUSSÃO DOS DADOS}

Foram analisadas 15 memórias e 11 entrevistas. O número de entrevistas é menor que o de memórias porque houve desistências das professoras no processo da formação continuada e o memorial foi uma das primeiras tarefas solicitadas.

As participantes da amostra foram do gênero feminino, formadas em pedagogia, e 12 das 15 professoras possuem pós-graduação. Esse dado revela que a formação das professoras estava de acordo com a Lei de Diretrizes e Bases da Educação (LDB, Lei 9.394/96) que, no artigo 61, determina que os profissionais da educação devem apresentar diploma de curso técnico ou superior em área pedagógica ou afim (BRASIL, 1996). 
As professoras atuam no ensino fundamental I ( $1^{\circ}$ ao $5^{\circ}$ ano), com tempo de docência em média de 3 a 6 anos, o que caracteriza um grupo novo de professoras atuantes nessa escola. Porém, no que diz respeito à experiência como docentes, varia, sendo que 5 professoras tinham atuado no magistério num intervalo de 17 a 20 anos, 2 professoras possuíam 10 anos na docência e 3 professoras apresentavam um tempo de docência de 5 a 7 anos.

Outro elemento importante a ser destacado é que 8 professoras tiveram outras profissões nas áreas de: comércio, costura, telemarketing, secretariado, contabilidade, entre outros. A seguir algumas das falas das professoras:

Consegui um emprego em uma multinacional, trabalhava como telemarketing. [...] abri um negócio próprio, uma loja de roupas (P3).

Resolvi tentar o comércio, trabalhei por pouco tempo, pois não me satisfazia (P5).

Optei pela costura até 40 anos (P8).

Logo comecei e trabalhar em uma loja de decorações (P9).

Atuava em uma empresa privada na área financeira, totalmente diferente (P12).

Cheguei a cursar, na Federal, engenharia elétrica (P14).

O que fez algumas professoras buscarem o caminho do magistério está relacionado ao sonho e ao desejo de se tornarem professoras e/ou à procura de algo novo que as realizasse profissionalmente. Como indicam os discursos:

Agora não consigo me imaginar em outra profissão que não a de professor (P1).

Matriculei no curso de pedagogia com muita alegria e emoção, um sonho realizado (P4).

Eu era menina quando decidi que seria professora. [...] Cheguei onde queria, realizei meu sonho de criança "ser professora", [...] posso dizer, que estou realizada profissionalmente (P5).

Ora, vejam, passei no concurso. Hoje, sou professora de escola, e estou feliz, gosto do que faço. A tarde sou professora, sonho conquistado (P6).

Consegui fixar vaga na Escola $\mathrm{X}$ e me sinto muito feliz, está escola é tudo que eu quero e sempre sonhei, tenho duas turmas (P7).

Os anos passaram de depois de 10 anos fiz outro concurso para professor onde atuo até hoje e estou muito feliz (P9). 
Eu sempre trabalhei com pessoas, em vários lugares, até que um dia resolvi fazer pedagogia, magistério e dar aula (P10).

Hoje, tenho plena convicção que minha profissão é tudo o que eu sonhava (P12).

Percebe-se, pelos discursos, uma satisfação muito grande em ser professora, independentemente de quando, em suas trajetórias de vida, isso aconteceu. Atualmente, como afirmaram, essas professoras se consideram realizadas do ponto de vista profissional.

Vale ressaltar que, de acordo com Fontoura (1992, p. 174), “[...] o ritmo rápido de transformações sociais, econômicas, políticas e culturais das sociedades contemporâneas traduz-se no quadro escolar pela complexidade crescente das funções atribuídas ao professor e pela exigência cada vez mais sentida de abrir a escola ao mundo e à modernidade”. As professoras apresentam uma satisfação pela profissão, mas mediante sua complexidade, discorrem sobre as dificuldades que marcam a docência, como ressaltam as falas a seguir:

Tenho consciência que não somos valorizados financeiramente (P5).

Tento somar minhas dificuldades da melhor maneira possível, buscando sempre me aperfeiçoar em corsos e estudos que venham a sugerir na escola (P6).

A vida profissional é cheia de desafios fiz pós-graduação em educação especial e sempre estou lendo e pesquisando, adoro dar aulas e me preparar para isso é muito prazeroso (P7).

Com tanto envolvimento com o magistério, acabei desistindo da confecção em larga escala, me formei em pedagogia e fiz pós-graduação em educação especial onde já exercia a profissão há 10 anos, ainda hoje faço cursos constantes de aperfeiçoamento e atualização, para trazer o melhor para os meus alunos (P8).

Nem todas as escolas possuem salas maravilhosas (P10).

Experimentei os encantamentos e desencantamentos da educação. Continuei com sede do saber, sempre estudando e procurando me especializar na área que atuo. [...] enfrentamos desafios árduos no cotidiano. Choramos, timos, temos raiva e em alguns momentos pensamos em desistir (P12).

Diante das dificuldades e exigências existentes na carreira docente, muitas professoras ressaltam a necessidade de se manterem atualizadas, levando em conta que, no processo de busca pela qualidade de ensino, a formação continuada dos professores pode ser considerada um elemento fundamental para a reflexão acerca das ações do trabalho pedagógico realizado na escola. A 
formação continuada entra como tema contribuinte para ampliar esse processo de aprendizagem docente, de forma a dar suporte ao exercício pedagógico.

Segundo Nóvoa (2002, p. 23), “O aprender contínuo é essencial e se concentra em dois pilares: a própria pessoa, como agente, e a escola, como lugar de crescimento profissional permanente". Assim, surge a necessidade de estar constantemente atualizado e envolvido com a melhoria da educação do nosso país e um dos meios que favorecem esse processo está na formação inicial e continuada.

Tardif (2012), ao referir-se à formação continuada, afirma que os professores possuem, produzem e utilizam saberes específicos de sua profissão e devem ser considerados sujeitos desse conhecimento. Sendo assim, o professor não deve ser considerado apenas um sujeito para uma pesquisa, mas como alguém que produz conhecimento e transforma o contexto em que se encontra.

Ao considerar a trajetória de vida, além dos elementos destacados, percebe-se a grande influência da família, pequenos acontecimentos e tomadas de decisões que contribuíram para a carreira das professoras. As narrativas a seguir mostram alguns dos elementos influenciadores no processo de tomada de decisão de se tornarem professoras:

Em 2003 estava desempregada e passei no concurso da Prefeitura Municipal de Curitiba para educadora (P1).

No começo eu tinha medo de fazer vestibular pois só ia mal no colégio imagine faculdade que era muito mais difícil. [...], mas passei e nunca peguei final na faculdade e consegui terminar nos 4 anos, isso me fez ainda mais querer ser professora (P2).

Com o apoio do noivo, familiares e amigos, a vida continuou seu rumo ( $\mathrm{P} 3$ - depois de anos voltou a estudar).

Abriu edital para concurso de Educadora na Prefeitura de Curitiba [... queria me estabilizar profissionalmente (P5).

Em um almoço em família, minha sogra comentou que riria iniciar o curso de magistério no município, perto de onde morava e isso chamou minha atenção (P12).

Para conseguir minha independência comecei a trabalhar muito cedo com 14 anos (P13).

Sempre fui privilegiada, pois meus pais estiveram muito presentes em todos os momentos dessa trajetória (P14). 
Segunda filha de quatro e filha de professores. [...] comecei a trabalhar em uma escolinha aos 14 anos o que foi decisivo (P15).

Além do suporte ou influência da família, a sensação de acolhimento e de pertença são elementos que marcam a decisão de algumas das professoras.

Outro fator influenciador é a busca de uma estabilidade profissional, adquirida por muitas por meio dos concursos públicos, e também a necessidade de trabalhar desde cedo. A construção da formação profissional mostrou-thes caminhos no decorrer do processo de docência.

Vale ressaltar que a proposta do memorial solicitava às professoras que destacassem elementos importantes que viveram e que, de certa forma, tivessem influenciado sua aprendizagem e trajetória de vida profissional. Por isso, em seus textos, os elementos que elas trazem - como influência da familia, trabalhar desde cedo, ter tido outras profissões, sonhar desde cedo em ser professora, busca da estabilidade - refletem a importância disso para suas trajetórias de vida. Não há, dessa forma, distanciamento entre o pessoal e o profissional.

\section{CONSIDERAÇÕES FINAIS}

Um dos caminhos para compreender a relação professor, aluno e conhecimento está em compreender como o professor tornou-se no professor que é hoje, uma vez que a trajetória profissional e pessoal refletem em seu ensino e na sua maneira de ser e estar professor.

Abordar as narrativas sobre as histórias de vida dos professores proporciona, ao professor, uma reflexão sobre o saber escolar, pois eles recordam de um passado e relembram fatos e experiências que motivaram e influenciaram sua escolha profissional. Essas experiências de vida também são importantes para os profissionais do ensino, pois possibilitam reconhecer a importância de integrar as dimensões pessoais com as dimensões profissionais das práticas do professor, como meio de potencializar os processos de sua formação.

Ao interpretar os memoriais e as entrevistas realizadas com um grupo de professoras do ensino fundamental, percebe-se que a história de vida das professoras é marcada por acontecimentos, experiências e processos que marcaram sua carreira e contribuíram para a construção de sua identidade docente.

Diante das análises, ressalta-se que as professoras se mostram realizadas profissionalmente, enfatizando o bem-estar pessoal e profissional de onde estão inseridas, mesmo diante da complexidade da profissão. O grupo de professoras participantes já possuía anos de experiência e falava com satisfação da profissão. Outro elemento a ser destacado é que docência nem sempre foi a 
primeira escolha profissional, mas que algumas professoras tiveram outras ocupações, tendo a docência acontecido depois, em virtude de uma série de acontecimentos ao longe de sua história de vida. Como exemplos, o sonho de ser professora e a busca de outra profissão que as realizarem profissionalmente.

$\mathrm{Na}$ escrita do memorial, a entrevista serviu como atividade reflexiva, uma vez que o professor recordou e refletiu sobre sua trajetória profissional, colocando-se como sujeito ativo da sua prática.

Recordar, refletir, reorganizar e ressignificar as histórias de vida pessoais e profissionais articuladas às memórias individuas e coletivas permitem ao professor reelaborar seu pensamento e dar sentido e significado a sua prática docente.

Nesse sentido, enfatiza-se a importância da elaboração do memorial, no qual o sujeito que narra sua própria história realiza um exercício reflexivo de aprendizagem, criatividade e fortalecimento da identidade profissional. Acredita-se, portanto, que a formação continuada é uma das ferramentas para a conscientização e sensibilização dos professores em relação as suas práticas, bem como para a tomada de decisão que potencialize as aprendizagens dos discentes nessa realidade complexa em que se situa a escola. 


\section{REFERÊNCIAS}

BRASIL. Lei 9.394, de 20 de dezembro de 1996. Estabelece as diretrizes e bases da educação nacional. Diário Oficial da União. Brasília: 23 dez. 1996. Disponível em: <http://www.planalto.gov.br/ccivil_03/leis/19394.htm>. Acesso em: 20 ago. 2018.

COSTA, Marisa V. (Org.). Caminhos Investigativos II: outros modos de pensar e fazer pesquisa em educação. 2 . ed. Rio de Janeiro: Lamparina Editora, 2007.

CANDAU, Vera Maria. (Org.). Magistério: construção e cotidiano. Petrópolis, RJ: Vozes, 1997.

FAZENDA, Ivani. (Org.). Metodologia da pesquisa educacional. 6. ed. São Paulo: Cortez, 2000.

FONTOURA, Maria M. Fico ou vou-me embora? In: NÓVOA, A. (Org.). Vidas de professores. Porto: Porto Editora, 1992. p. 171-198.

GONÇALVES, J. A. Desenvolvimento profissional e carreira docente - Fases da carreira, currículo e supervisão. Sísifo - Revista de Ciências da Educação, 8, p. 23-36, 2009.

GOODSON, Ivor F. Dar voz ao professor: as histórias de vida dos professores e o seu desenvolvimento profissional. In: NÓVOA, António. (Org.). Vidas de professores. Porto: Porto Editora, 1992. p. 63-78.

HALBW ACHS, Maurice. A memória coletiva. São Paulo: Vértice, 1990.

KRAMER, Sonia. Leitura e escrita de professores: da prática de pesquisa à prática de formação. Revista Brasileira de Educação, n. 7, p. 19-41, jan./abr. 1998.

MOITA, Maria da Conceição. Percursos de formação e de transformação. In: NÓvOA, A. (Org.). Vidas de professores. Portugal: Porto Editora, 1992. p. 111-140.

NÓVOA, António. (Org.). Vidas de professores. 2. ed. Portugal: Porto Editora, 1992.

Diz-me como ensinas, dir-te-ei quem és e vice-versa. In: FAZENDA, I. A pesquisa em educação e as transformações do conhecimento. Campinas, SP: Papirus, 1997. p. 29-41.

. Os novos pensadores da educação. Revista Nova Escola, n. 154, p. 23, ago. 2002.

ROMANOWSKI, Joana. P. Formação e profissionalização docente. 4. ed. Curitiba: Ibpex, 2010.

TARDIF, Maurice. Saberes docentes e formação profissional. Petrópolis: Vozes, 2012.

TREVISAN, Amarildo. L.; TOMAZETTI, Elizete. M.; ROSSATTO, Noeli. D. (Orgs.). Diferença, cultura e educação. Porto Alegre: Sulina, 2010. 


\section{RESUMO}

O artigo objetivou descrever e interpretar a trajetória de vida profissional das professoras participantes de um Programa de Formação Continuada oferecido por um grupo de pesquisadores de uma instituição privada de educação superior, durante o ano de 2017, na cidade de Curitiba, Paraná, para professoras do ensino fundamental I. A escrita do memorial e a realização de entrevistas semiestruturadas, foram analisadas por meio da fenomenologia hermenêutica, uma vez que esta não apenas descreve e analisa as vozes, as falas e a linguagem do sujeito, mas interpreta o que este meio comunica. Os dados revelam que as professoras têm grande satisfação com a profissão mesmo diante das dificuldades e exigências que acompanham a docência.

Palavras-chave: Memórias. Formação docente. História de vida.

\section{MEMORIES OF TEACHERS: THE CHOICE OF TEACHING PROFESSION}

\section{ABSTRACT}

The article aimed to describe and interpret the professional life trajectory of the teachers participating in a Continuing Education Program offered by a group of researchers from a private institution of higher education during the year 2017 in the city of Curitiba, Paraná, for teachers of the elementary education I. The writing of the memorial and the realization of semistructured interviews were analyzed through hermeneutic phenomenology, since it not only describes and analyzes the voices, the speeches and the language of the subject, but interprets what this means communicates. The data reveal that the teachers have great satisfaction with the profession even in the face of the difficulties and demands that accompany the teaching.

Keywords: Memories. Teacher training. Life's history.

\section{MEMORIAS DE PROFESORAS: LA ELECCIÓN DE LA PROFESIÓN DOCENTE}

\section{RESUMEN}

El artículo objetivó describir e interpretar la trayectoria de vida profesional de las profesoras participantes de un Programa de Formación Continuada ofrecido por un grupo de investigadores de una institución privada de educación superior durante el año 2017 en la ciudad de Curitiba, Paraná, para profesoras del mismo, La escritura del memorial y la realización de entrevistas semiestructuradas, fueron analizadas por medio de la fenomenología hermenéutica, ya que ésta no sólo describe y analiza las voces, las palabras y el lenguaje del sujeto, sino que interpreta lo que este medio comunica. Los datos revelan que las profesoras tienen gran satisfacción con la profesión incluso ante las dificultades y exigencias que acompañan a la docencia.

Palabras clave: Memorias. Formación docente. Historia de vida.

Submetido em: 22 de outubro de 2018 Aprovado em: 30 de abril de 2019 